\title{
New national consortium to tackle anti- Indigenous racism in medical education
}

\author{
— Cite as: CMAJ 2021 March 8;193:E347. doi: 10.1503/cmaj.1095925
}

Posted on cmajnews.com on February 19, 2021

ndigenous medical leaders across Canada have formed a national consortium on Indigenous medical education to collaborate on anti-racist reforms and culturally safe care.

For years, this work has fallen to individual educators and physicians at different organizations, said Dr. Lisa Richardson, strategic advisor of Indigenous health at the University of Toronto's Temerty Faculty of Medicine. However, "the same work needs to be done across institutions and all faculties of medicine or health sciences."

The new consortium will bring together the Indigenous Physicians Association of Canada, the Association of Faculties of Medicine of Canada, the Medical Council of Canada, the College of Family Physicians of Canada and the Royal College of Physicians and Surgeons of Canada, with funding from the federal government.

According to Richardson, an executive member of the consortium, the partnership will provide a structure for "collaboration, sharing, dissemination and knowledge translation... so that the same people aren't being asked to do the same thing all the time at these different institutions."

The consortium aims to create antiracist policies and curriculum across Canada's medical schools to make health care safer for Indigenous trainees, physicians, educators and patients. Richardson noted that non-Indigenous people will benefit from many of these changes too.

Working groups within the organization will tackle anti-racism, medical school admissions, transition into residency and practice, curriculum and assessment, and recruitment and retention of Indigenous

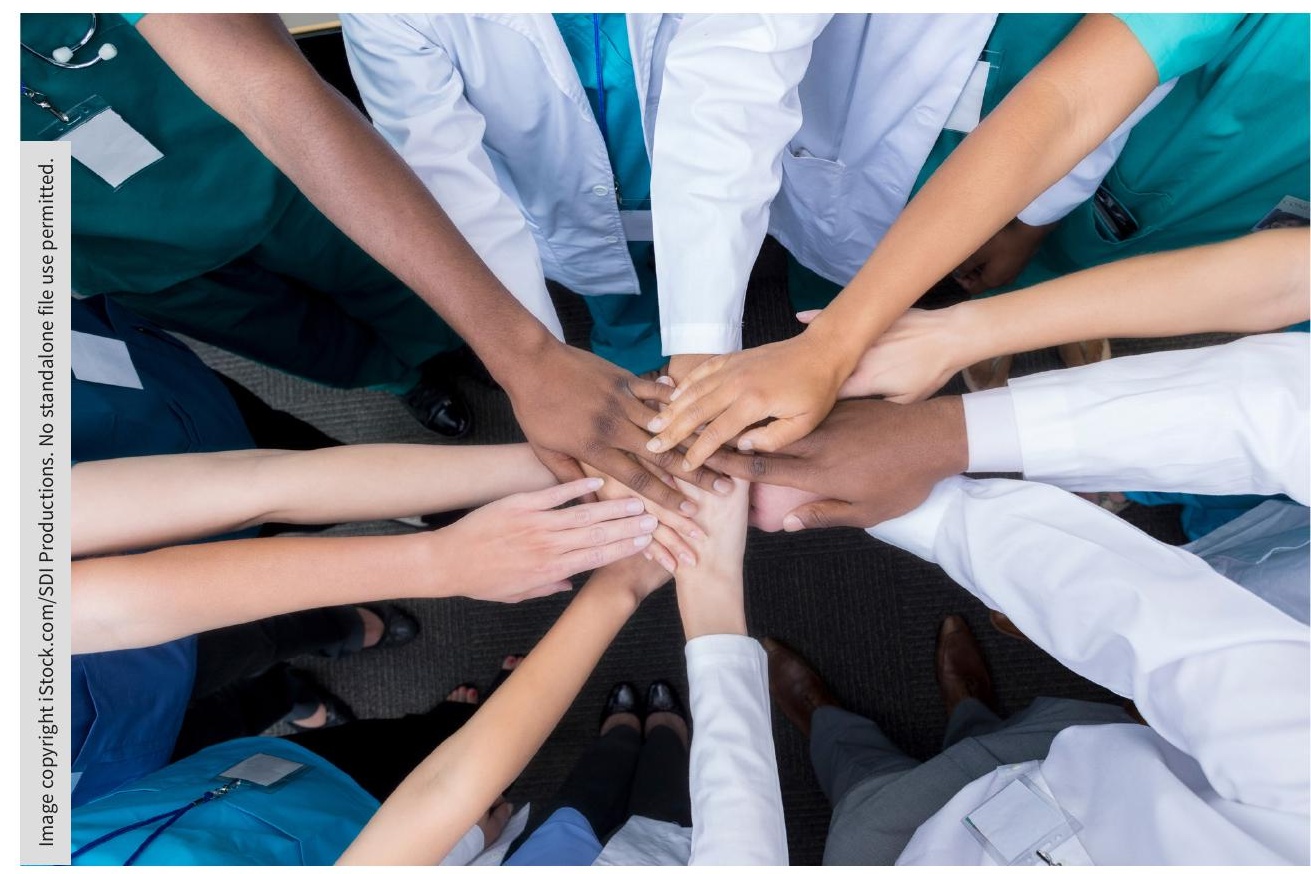

A new Indigenous-led consortium will work together on anti-racism efforts across Canada's medical schools.

faculty. Because Indigenous physicians face high rates of burnout, the consortium also aims to support physician wellness.

According to Dr. Marcia Anderson, chair of the consortium, it's an important step toward addressing anti-Indigenous racism in medical education and health care. "Training physicians who can practice medicine in ways that meet the needs of Indigenous Peoples requires Indigenous leadership, learning environments that are free of racism, and assessment processes that ensure physicians have anti-racism and cultural safety knowledge and skills."

Achieving these goals will require widespread structural reforms, Anderson stated. "We are committed to working with all partners to implement Indigenous-led solutions in health care education and service delivery."

The secretariat for the consortium is housed at the Association of Faculties of Medicine of Canada, but its oversight and executive will transition to the Indigenous Physicians Association of Canada to remain within an Indigenous organization.

\section{Diana Duong, CMAJ}

Content licence: This is an Open Access article distributed in accordance with the terms of the Creative Commons Attribution (CC BY-NC-ND 4.0) licence, which permits use, distribution and reproduction in any medium, provided that the original publication is properly cited, the use is noncommercial (i.e., research or educational use), and no modifications or adaptations are made. See: https://creativecommons.org/ licenses/by-nc-nd/4.0/ 